\title{
Investigation of the incidence of "undesirable" molecular moieties for high-throughput screening compound libraries in marketed drug compounds P Axerio-Cilies ${ }^{1,2}$, IP Castañeda1,2, A Mirza ${ }^{1}$ and J Reynisson*3
}

\begin{abstract}
Address: ${ }^{1}$ Cancer Research UK Centre for Cancer Therapeutics, Institute of Cancer Research, 15 Cotswold Road, Sutton, Surrey, SM2 5NG, UK, ${ }^{2}$ London Metropolitan University, Department of Health and Human Sciences, Holloway Road, London, N7 8DB, UK and ${ }^{3}$ Nottingham Trent University, School of Science and Technology, Clifton Lane, Nottingham, NG11 8NS, UK

* Corresponding author
\end{abstract}

from 4th German Conference on Chemoinformatics

Goslar, Germany. 9-II November 2008

Published: 5 June 2009

Chemistry Central Journal 2009, 3(Suppl I):P2 doi:10.1186/I752-I53X-3-SI-P2

This abstract is available from: http://www.journal.chemistrycentral.com/content/3/SI/P2

(c) 2009 Axerio-Cilies et al; licensee BioMed Central Ltd.

A database of 1070 marketed drug compounds was compiled and analyzed in order to assess the occurrence of moieties described in the literature as "undesirable" for high-throughput screening compound libraries due to their ability to perturb assay formats [1][2][3]. The study revealed a total of 277 compounds, $26 \%$ of the database, contained at least one of the moieties. As some of the drug compounds contained more than one "undesirable" moiety, the total number was 352. Electrophilic reactive groups, particularly aliphatic esters, were the most abundant type with $55 \%$ of the total. Half of the drug compounds incorporating the "undesirable" moieties were synthetic organic molecules. These findings suggest that "undesirable" moieties do not pose a major hindrance during clinical trials, the most expensive phase of drug development. In addition, their early elimination in the preclinical stage excludes large regions of known drug space due to the reliance on biochemical and cell-based assays. In general, it can be concluded that compounds with "undesirable" moieties should not simply be eliminated from compound screening libraries but rather flagged as potentially problematic. A possible solution is to segregate the compounds containing suspect moieties and screen them when deemed appropriate.

\section{References}

I. Rishton GM: DDT 1997, 2:382-384.

2. Rishton GM: DDT 2003, 8:86-96.

3. Roche O, Schneider P, Zuegge J, Guba W, Kansy M, Alanine A, Bleicher K, Danel F, Gutknecht EM, Rogers-Evans M, Neidhart W,
Stalder H, Dillon M, Sjogren E, Fotouhi N, Gillespie P, Goodnow R, Jones HWP, Taniguchi M, Tsujii S, Saal W von der, Zimmermann G, Schneider G: J Med Chem 2002, 45:137-142. 